\title{
Influence of Vagal Activity on the Neonatal Ventilatory Response to Hypoxemia
}

\author{
WILLIAM A. LAFRAMBOISE. ${ }^{\prime}$ DAVID E. WOODRUM, AND ROBERT D. GUTHRIE' \\ Department of Pediatrics, Division of Neonatal and Respiratory Diseases, University of Washington, \\ Seattle, Washington 98195
}

\begin{abstract}
The sustained increase in ventilation $\left(\dot{V}_{\mathrm{l}}\right)$ that occurs during acute hypoxemia in adults is not characteristic of the neonate as $\dot{V}_{1}$ falls to or below baseline values soon after onset of the hypoxic stimulus. Associated with this decline in $\dot{V}_{1}$ is a decrease in tidal volume, lung compliance, inspiratory duration, and an increase in functional residual capacity and respiratory frequency. We hypothesized that hypoxemia induced small airway constriction and pulmonary time constant inequalities resulting in a frequency dependent fall in lung compliance and tidal volume and retention of lung volume. In seven newborn subhuman primates, responses to acute hypoxemia were measured prior to and after administration of atropine methyl bromide to prevent vagally mediated narrowing of peripheral airways. The increase in frequency and fall in inspiratory duration characteristic of the ventilatory decline during hypoxemia was eliminated by the drug but functional residual capacity and lung compliance were unaffected. Also, the initial rise in $\dot{V}_{I}$ was blunted or blocked in all subjects. Bilateral vagotomy caused $\dot{V}_{1}$ to fall significantly requiring oxygen supplementation but responses to hypoxemia were still biphasic in nature. These findings suggest that cholinergically mediated mechanisms in the airways do not alter effective lung distensibility related to respiratory rate. Acetylcholine may be important at the peripheral chemosensor since cholinergic blockade eliminated the initial ventilatory increase. Finally, although vagotomy radically affected respiratory pattern during eupnea and hypoxia, the ventilatory response to hypoxemia remained biphasic ruling out this pathway as a primary modulator in the newborn response. (Pediatr Res 19: 903907, 1985)
\end{abstract}

\section{Abbreviations}

FRC, functional residual capacity

$V_{T}$, tidal volume

$\mathrm{T}_{\mathrm{i}}$, inspiratory duration

The hypoxic ventilatory response of the human neonate and the newborn of other animal species is characterized by a transient increase in minute ventilation followed by a return to baseline values despite the continued presence of arterial hypoxemia (1-4). Recent studies performed in subhuman primates and kittens have shown that the ventilatory decline cannot be

Received January 10. 1985: accepted April 15. 1985

Reprint requests William A. LaFramboise. Magee-Womens Hospital. Department of Pediatrics. Division of Neonatology. Forbes Avenue and Haiket Street. Pittsburgh. PA 15213.

Supported in part by NIH Grant HL19198 and Regional Primate Center Grant RR00166.

${ }^{1}$ Present address Department of Pediatrics. Division of Neonatology, University of Pittsburgh. School of Medicine, Magee-Womens Hospital. Pittsburgh, PA 15213. attributed solely to central neural hypoxic depression since airway occlusion pressures and phrenic neural activity remain elevated even as ventilation falls $(1,3)$.

Data collected in these and other studies suggest that the biphasic ventilatory pattern may result from changes in respiratory mechanics $(3,5)$. Dynamic lung compliance falls during hypoxemia in the newborn monkey but not in older subhuman primates who sustain an elevated ventilatory output (5). FRC was consistently increased in the newborn monkeys during the late phase of the ventilatory response (5-7 min after the stimulus) and this also did not occur in the older monkeys $(3,5)$. In addition, inspiratory pulmonary resistance did not decrease during hypoxemia as would be expected in light of the marked increases in FRC which occurred.

The failure to decrease pulmonary resistance despite a significant elevation in FRC led us to suspect that the primary event in these mechanical and ventilatory changes was a hypoxiainduced constriction of the neonatal airways and in particular the peripheral airways. Since the peripheral airways constitute a considerably larger component of the total pulmonary resistance in the newborn than the adult, a change in peripheral airways caliber would be expected to have a greater effect on neonatal pulmonary function (6). Should a hypoxic-induced peripheral airway constriction be present in the newborn as has been shown to occur in the adult, time constant inequalities could develop between lung regions particularly as respiratory frequency increased during the late phase of the biphasic response $(7,8)$. Such time contant changes have been shown to cause asynchronous ventilation between lung regions, a decrease in tidal volume and lung compliance, and a subsequent retention of end-expiratory lung volume $(5,7)$-all characteristic changes which have been documented during hypoxemia in the subhuman primate.

To test the relationship between these mechanical parameters and their effect on the neonatal response to hypoxemia, we administered a systemic cholinergic antagonist, methyl-atropine, to block efferent vagal activity and thereby prevent peripheral airway constriction (8-12). By inhibiting changes in small airway diameter we sought to prevent the hypoxic-induced alterations in compliance and FRC. If our hypothesis was correct we anticipated that the newborn would subsequently maintain an increased ventilatory output during hypoxemia.

\section{METHODS}

Seven infant Macaca nemestrina were delivered by cesarean section at the same gestational age (158 \pm 2 days) and studied according to a previously published protocol at $48 \mathrm{~h}$ of age (3). Studies were performed as the infants slept with a tracheostomy tube connected to a low resistance nonrebreathing valve. An umbilical arterial cannula placed at birth was available for obtaining blood gas samples and monitoring blood pressure and heart rate.

Inspiratory flow was measured using a hot wire anemometer located downstream in the flow of gas feeding the inspiratory port of the nonrebreathing valve (13). After electronic integration 
(Hewlett-Packard 8815-A) of the inspiratory flow changes and by operating the chart recorder at high speed $(100 \mathrm{~mm} / \mathrm{s})$, we were able to obtain volumetric and timing components of minute ventilation $-\mathrm{V}_{\mathrm{T}}, \mathrm{T}_{\mathrm{i}}$ and total breath duration. Other parameters, e.g. mean inspiratory flow $\left(\mathrm{V}_{\mathrm{T}} / \mathrm{T}_{\mathrm{i}}\right)$ and inspiratory duty time $\left(\mathrm{T}_{\mathrm{i}} /\right.$ total breath duration) were calculated.

Esophageal pressures were monitored by passing a $15-\mathrm{cm}$ long, water-filled catheter $(1.4 \mathrm{~mm}$ ID) through the mouth and into the distal esophagus just above the cardiac sphincter $(\sim 1 \mathrm{~cm})$ where the inspiratory pressures were greatest and cardiac artifact absent. Esophageal pressures were sensed by a pressure transducer (Gould P-50) located on the end of the fluid-filled catheter. Upper airway pressure was measured by a similar pressure transducer connected to a sidearm on the tracheal tube.

FRC was determined utilizing the $\mathrm{N}_{2}$-washout technique as the monkey was switched from the inspired gas to $100 \%$ oxygen. Expired tidal air was collected in a neoprene rubber bellows and the FRC calculated according to Fowler (14).

The protocol for this study involved collecting data during a room air control period while the subject was asleep. Then the animal breathed $10-12 \% \mathrm{O}_{2}$ for a 5 - to 7 -min period, during which time arterial oxygen levels decreased to approximately 20 torr. Ventilatory and timing data, dynamic lung compliance, and arterial gases were measured during the room air control period and during the early (1-2 min after stimulus) and late (57 min after stimulus) phases of the hypoxic ventilatory response. Intermittent end-expiratory airway occlusions were performed as an index of inspiratory drive (15) at these time periods. FRC was measured while the subjects breathed air prior to hypoxemia and at the end of the period of hypoxemia. Two runs were repeated on each subject with at least 20 min of recovery time between hypoxic stimuli.

After successful completion of these studies, $1.0 \mathrm{mg} / \mathrm{kg}$ of Atr $\mathrm{Me} \mathrm{Br}$, a quaternary atropine salt unable to cross the blood-brain barrier, was administered for systemic efferent vagal blockade (16). Initial effect of the drug was visible in a transient heart rate and blood pressure augmentation. After 15-30 min had elapsed, the hypoxic ventilatory responses were repeated in each subject with lung compliance, end-expiratory occlusions, and FRC measurements repeated for comparison with predrug values.

To elucidate further the contribution of vagal activity to the biphasic ventilatory pattern, we bilaterally isolated and then cut the vagus nerve in four of the infants following ketamine anesthesia. After recovery from the effects of the ketamine $(\sim 1 \mathrm{~h})$, these subjects were made hypoxic in the same manner employed prior to vagotomy and ventilatory measurements collected.

Statistical testing of the data was carried out utilizing the Student's $t$ test for paired variables. Percentage changes from

Table 1. Volumetric, drive, and timing components of ventilation (mean $\pm S D, n=7$ )*

\begin{tabular}{|c|c|c|c|c|c|c|}
\hline & \multicolumn{3}{|c|}{ Predrug } & \multicolumn{3}{|c|}{ Postdrug } \\
\hline & Baseline & 1'Hypoxemia & 5'Hypoxemia & Baseline & 1'Hypoxemia & 5'Hypoxemia \\
\hline$\dot{\mathrm{V}}_{\mathrm{I}}\left(\mathrm{ml} \cdot \mathrm{min}^{-1}\right)$ & $144 \pm 33$ & $\begin{array}{l}180 \pm 45 \\
p<0.025\end{array}$ & $\begin{array}{c}142 \pm 37 \\
\text { NS }\end{array}$ & $155 \pm 42$ & $\begin{array}{c}142 \pm 33 \\
\mathrm{NS}\end{array}$ & $\begin{array}{l}127 \pm 41 \\
p<0.005\end{array}$ \\
\hline $\mathrm{V}_{\mathrm{T}}(\mathrm{ml})$ & $2.34 \pm 0.42$ & $\begin{array}{c}2.64 \pm 0.36 \\
\text { NS }\end{array}$ & $\begin{array}{c}2.01 \pm 0.29 \\
\text { NS }\end{array}$ & $2.40 \pm 0.42$ & $\begin{array}{c}2.24 \pm 0.29 \\
\text { NS }\end{array}$ & $\begin{array}{c}1.97 \pm 0.36 \\
p<0.005\end{array}$ \\
\hline (breaths. $\min ^{-1}$ ) & $62 \pm 13$ & $\begin{array}{c}68 \pm 12 \\
\mathrm{NS}\end{array}$ & $\begin{array}{r}71 \pm 15 \\
p<0.05\end{array}$ & $64 \pm 12$ & $\begin{array}{c}64 \pm 14 \\
\mathrm{NS}\end{array}$ & $\begin{array}{c}65 \pm 18 \\
\mathrm{NS}\end{array}$ \\
\hline$T_{i}(s)$ & $0.50 \pm 0.09$ & $\begin{array}{c}0.45 \pm 0.09 \\
\text { NS }\end{array}$ & $\begin{array}{c}0.42 \pm 0.08 \\
p<0.025\end{array}$ & $0.50 \pm 0.10$ & $\begin{array}{c}0.48 \pm 0.10 \\
\text { NS }\end{array}$ & $\begin{array}{c}0.50 \pm 0.15 \\
\mathrm{NS}\end{array}$ \\
\hline $\mathrm{V}_{\mathrm{T}} / \mathrm{T}_{\mathrm{i}}\left(\mathrm{ml} \cdot \mathrm{s}^{-1}\right)$ & $4.69 \pm 0.77$ & $\begin{array}{c}6.13 \pm 1.46 \\
p<0.025\end{array}$ & $\begin{array}{c}4.89 \pm 0.90 \\
\text { NS }\end{array}$ & $4.96 \pm 1.03$ & $\begin{array}{c}4.83 \pm 0.89 \\
\mathrm{NS}\end{array}$ & $\begin{array}{c}4.22 \pm 1.17 \\
p<0.005\end{array}$ \\
\hline $\mathrm{P}_{0.2}\left(\mathrm{~cm} \mathrm{H}_{2} \mathrm{O}\right)$ & $3.4 \pm 0.8$ & $\begin{array}{l}5.2 \pm 1.9 \\
p<0.05\end{array}$ & $\begin{array}{l}4.4 \pm 0.8 \\
p<0.05\end{array}$ & $4.0 \pm 0.8$ & $\begin{array}{c}4.4 \pm 0.5 \\
\mathrm{NS}\end{array}$ & $\begin{array}{c}4.7 \pm 1.1 \\
\mathrm{NS}\end{array}$ \\
\hline
\end{tabular}

*Abbreviations: $\dot{V}_{\mathrm{I}}$, minute ventilation; $f$, frequency; respiratory rate; $T_{i}$, inspiratory flow; $V_{T} T_{i}$, mean inspiratory flow; $P_{0.2}$, airway pressure generated 200 milliseconds into an occluded inspiration. Statistical comparisons made from baseline to particular stimulus period (1-or 5-min data).

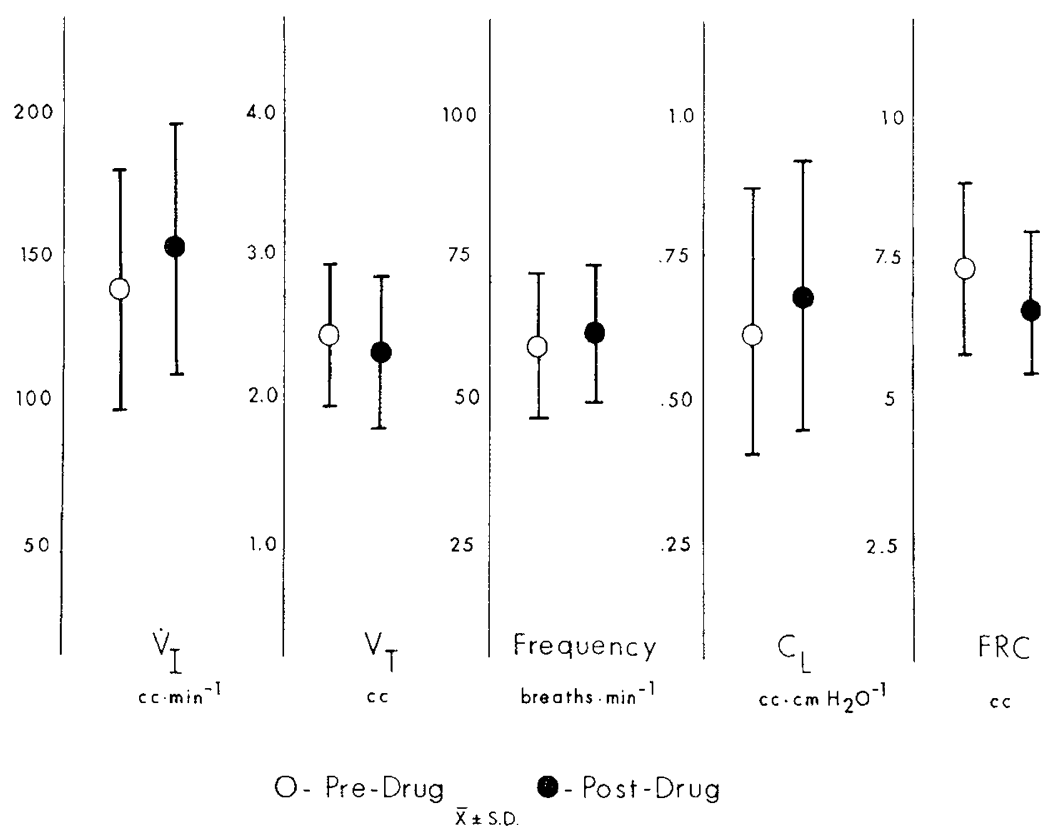

Fig. 1. The effect of Atr Me $\mathrm{Br}$ on baseline respiratory parameters obtained while the subjects were breathing air. There were no statistical differences among these variables when compared for drug-induced changes. 
Table 2. Arterial blood gas values (mean $\pm S D, n=7$ )*

\begin{tabular}{|c|c|c|c|c|c|c|}
\hline & \multicolumn{3}{|c|}{ Predrug } & \multicolumn{3}{|c|}{ Postdrug } \\
\hline \multirow[b]{2}{*}{$\mathrm{PaO}_{2}$ (torr) } & Baseline & I'Hypoxemia & 5'Hypoxemia & Baseline & 1'Hypoxemia & 5'Hypoxemia \\
\hline & $77 \pm 15$ & $\begin{array}{c}28 \pm 2 \\
p<0.001\end{array}$ & $\begin{array}{c}20 \pm 3 \\
p<0.001\end{array}$ & $73 \pm 14$ & $\begin{array}{c}30 \pm 7 \\
p<0.001\end{array}$ & $\begin{array}{c}21 \pm 6 \\
p<0.001\end{array}$ \\
\hline $\mathrm{PaCO}_{2}$ (torr) & $39 \pm 4.3$ & $\begin{array}{r}36 \pm 4.3 \\
p<0.025\end{array}$ & $\begin{array}{c}37 \pm 6.2 \\
\text { NS }\end{array}$ & $39 \pm 3.5$ & $\begin{array}{c}37 \pm 3.8 \\
\mathrm{NS}\end{array}$ & $\begin{array}{c}38 \pm 5.4 \\
\text { NS }\end{array}$ \\
\hline $\mathrm{pH}$ & $7.37 \pm 0.03$ & $\begin{array}{l}7.40 \pm 0.09 \\
p<0.05\end{array}$ & $\begin{array}{c}7.39 \pm 0.09 \\
\text { NS }\end{array}$ & $7.36 \pm 0.03$ & $\begin{array}{c}7.41 \pm 0.06 \\
\text { NS }\end{array}$ & $\begin{array}{c}7.40 \pm 0.04 \\
\text { NS }\end{array}$ \\
\hline
\end{tabular}

* The level of hypoxemia utilized prior to administration of Atr Me $\mathrm{Br}$ was matched during the drug studies. None of the blood gas values was significantly altered between control and drug studies.
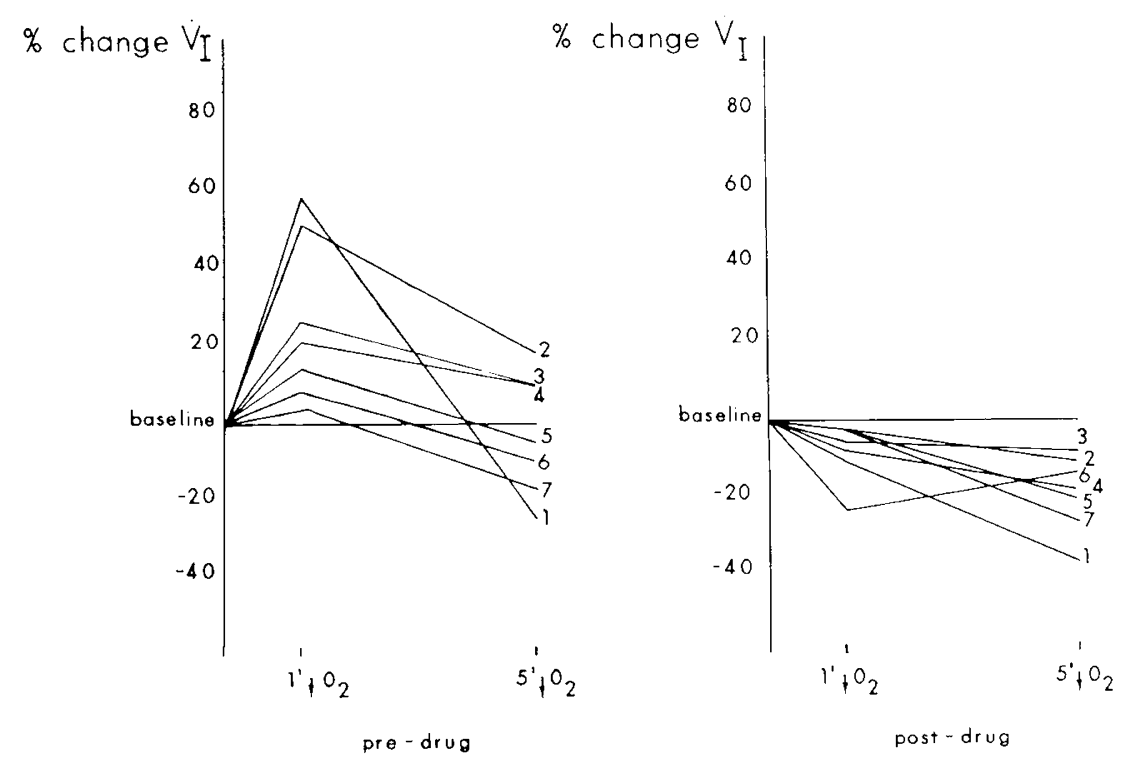

Fig. 2. Average ventilatory response for each of seven subjects obtained prior to and after administration of Atr Me Br. Statistics are reported on actual data in Table 1. A minimum of two runs were performed in each condition and the plotted point is the mean. There where instances at $1^{\prime}$ of hypoxemia after the drug was given when ventilation reached values above the baseline but this never occurred at the $5^{\prime}$ measurements.

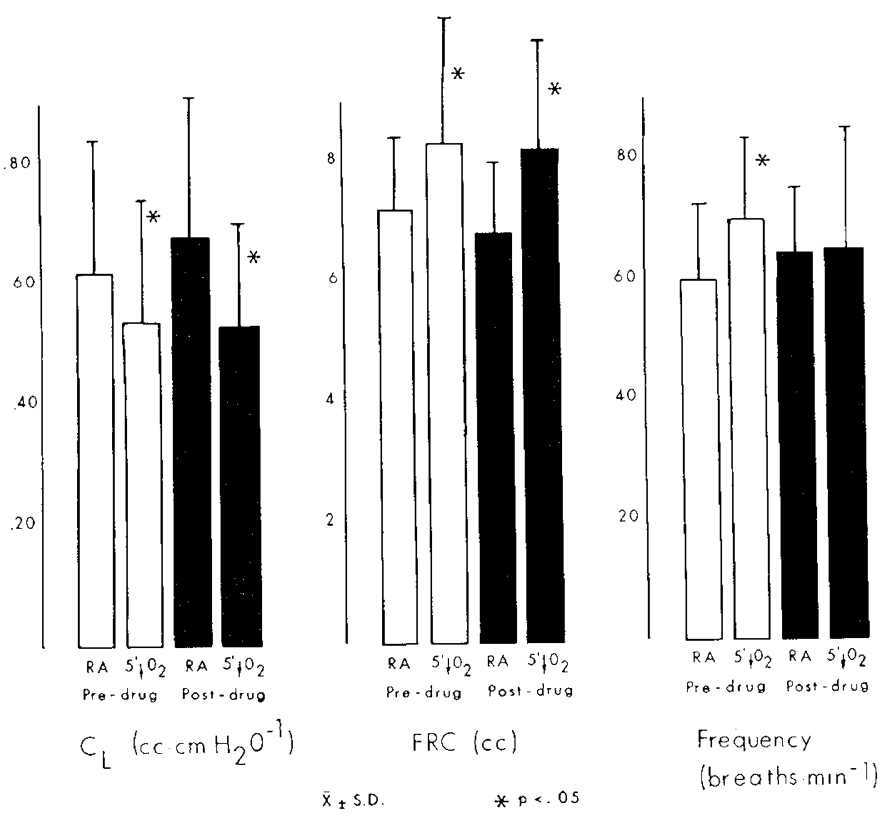

Fig. 3. Effect of Atr Me Br on compliance, resting lung volume, and respiratory frequency during hypoxemia. Atr $\mathrm{Me} \mathrm{Br}$ did not alter the fall in lung compliance $\left(C_{\mathrm{L}}\right)$ or the increase in FRC induced by hypoxemia. The increase in frquency which occurred during hypoxemia prior to drug injection was not present afterwards $(n=7)$.
Table 3. Ventilatory parameters and blood gases after vagotomy $(\text { mean } \pm S D, n=4)^{*}$

\begin{tabular}{lccc}
\hline & Baseline & $1^{\prime} \downarrow \mathrm{O}_{2}$ & $5^{\prime} \downarrow \mathrm{O}_{2}$ \\
\hline$\dot{\mathrm{V}}_{\mathrm{I}}\left(\mathrm{ml} \cdot \mathrm{min}^{-1}\right)$ & $87 \pm 31$ & $145 \pm 59$ & $94 \pm 46$ \\
& & $p<0.025$ & $\mathrm{NS}$ \\
$\mathrm{V}_{\mathrm{T}}(\mathrm{ml})$ & $7.4 \pm 4.2$ & $8.9 \pm 2.1$ & $7.3 \pm 3.1$ \\
& & $\mathrm{NS}$ & $\mathrm{NS}$ \\
$\mathrm{f}\left(\right.$ breaths $\left.\cdot \mathrm{min}^{-1}\right)$ & $12 \pm 3.0$ & $16 \pm 6.0$ & $13 \pm 4.7$ \\
& & $p<0.05$ & $\mathrm{NS}$ \\
$\mathrm{PaO}_{2}$ (torr) & $68 \pm 17$ & $32 \pm 6$ & $22 \pm 3.0$ \\
& & $p<0.005$ & $p<0.005$ \\
$\mathrm{PaCO}_{2}$ (torr) & $45 \pm 4$ & $40 \pm 12$ & $44 \pm 12$ \\
& & $p<0.05$ & $\mathrm{NS}$ \\
\hline
\end{tabular}

* Data coded as in Table 1. Minute ventilation and frequency fell statistically when compared to prevagotomy values $(p<0.025$ by unpaired $t$ test with Table 1 values) while $\mathrm{V}_{\mathrm{T}}$ and $\mathrm{PaCO}_{2}$ were significantly elevated $(p<0.001)$. These subjects received supplemental oxygen $(\sim 30 \%)$ to achieve a normal $\mathrm{PaO}_{2}$ level in comparison with prevagotomy values.

baseline were tested on variables obtained during hypoxemia prior to and after drug administration using the paired $t$ test to determine whether the hypoxic response was statistically altered. A $p$ value of less than 0.05 was accepted to represent a statistically significant difference. 


\section{RESULTS}

All animals demonstrated a biphasic ventilatory pattern prior to administration of Atr $\mathrm{Me} \mathrm{Br}$ with the rise and fall in $\dot{V}_{\mathrm{I}}$ associated with an increase and then decrease in tidal volume (Table 1). These $V_{T}$ changes were somewhat offset in the declining phase of an increase in respiratory frequency secondary to a progressive reduction in inspiratory time. The increase in frequency occurred concomitant with a significant increase in FRC and a decrease in dynamic lung compliance as has been demonstrated previously in this species $(3,5)$.

Systemic administration of Atr Me Br resulted in an immediate but transient rise in blood pressure and heart rate. Baseline ventilation, ventilatory pattern, and blood gases were not altered significantly by the drug (Fig. 1 and Table 2 ).

The effect of the drug on the ventilatory output of the subjects during hypoxemia is displayed in Figure 2. The ventilatory pattern was no longer biphasic but rather $\dot{V}_{1}$ declined during the first minute and continued below baseline in the fifth minute of hypoxemia. The decrease in lung compliance and increase in FRC which existed during hypoxemia prior to the drug were also present in the postdrug studies despite the fact that breathing frequency was no longer increased (Fig. 3).

Bilateral vagotomy induced apnea of $1-2$ min followed by a gasping pattern of breathing which prevailed for the duration of the study. $V_{\mathrm{T}}$ increased approximately four times prevagotomy values and frequency fell far below normal values with $2-3 \mathrm{~s}$ pauses between breaths (Table 3 ). $\dot{V}_{1}$ during room air breathing fell significantly below prevagotomy levels with a concurrent increase in $\mathrm{PaCO}_{2}$ and decrease in $\mathrm{PaO}_{2}$. Supplemental oxygen was added to the inspired gas to match arterial $\mathrm{PaO}_{2}$ to the values present before vagotomy.

During hypoxemia, minute ventilation was again biphasic as before vagal denervation but in this case the changes in $\dot{V}_{1}$ were predominantly attributable to an increase and then decrease in respiratory frequency. Blood pressure fell during hypoxemia in each subject to a level $5-10 \mathrm{~mm} \mathrm{Hg}$ below baseline after $5 \mathrm{~min}$ of the hypoxic stimulus. Changes in esophageal tone and the uncharacteristic breathing pattern present after vagotomy prevented us from obtaining consistent measures of pulmonary mechanics during hypoxemia.

\section{DISCUSSION}

The hypothesis that a vagally mediated peripheral airway constriction is responsible for the observed increase in FRC and decrease in lung compliance during neonatal hypoxemia in the newborn monkey is not supported by the results of this study. Despite the presence of a systemic cholinergic antagonist, FRC increased and dynamic lung compliance fell in the subhuman primate during a hypoxic ventilatory challenge as previously reported (5). Respiratory rate did not increase significantly during hypoxemia after administration of Atr $\mathrm{Me} \mathrm{Br}$; therefore, the subsequent fall in compliance cannot be considered frequency dependent. These findings lead us to conclude that during neonatal hypoxemia, intrinsic cholinergically mediated mechanisms in the lungs and airways do not alter effective lung distensibility and do not cause lung volume retention. The observed increase in FRC is caused by other as yet unknown mechanisms.

How then, can we account for the observed decrease in compliance and increase in FRC during the late ventilatory response to hypoxemia in the neonatal primate? One alternative explanation is that the FRC increase rather than the drop in compliance is the direct result of hypoxemia. Enhancement of intercostal and/or accessory respiratory muscle activity triggered by acute hypoxemia could stiffen the chest wall, making it a more efficient pressure generator which would be a distinct advantage since the neonate has a flaccid chest wall prone to collapse during stimulated breathing. The FRC changes which might occur secondary to this maneuver may shift the inspiratory cycle to a flatter portion of the lung pressure-volume curve and explain the decrease in lung compliance. This theory presumes that the trade off of thoracic rigidity for reduced lung compliance is worthwhile in maximizing ventilatory output for effort expended. An investigation of chest wall stiffness and intercostal muscle activity during neonatal hypoxemia must be undertaken to prove this theory.

The transient ventilatory increase which characterizes the initial phase of the neonatal hypoxic response was either reduced or eliminated by systemic cholinergic inhibition. This observation is of significant importance and has not been demonstrated previously. If the drug did not cross the blood-brain barrier as is the case in adults (16), it is conceivable that the site of action was in the acetylcholine-mediated transduction mechanisms within the carotid body or in the cholinergic control of blood flow to the carotid glomus cells (17). Consequently, the immediate ventilatory increase of the neonate to a hypoxic stimulus was blocked. The fact that occlusion pressures were not statistically elevated during the postdrug studies while they were in the predrug studies indirectly supports this argument that peripheral chemosensor output was inhibited. Since we cannot exclude the possibility of some penetration of methyl atropine to the central nervous system, we cannot rule out direct inhibition of central neural cholinergic activity as the cause of the diminished hypoxic sensitivity.

The effect of bilateral vagotomy on resting breathing pattern was dramatic. Volume and flow mediated sensory feedback was eliminated or markedly reduced and the resulting respiratory pattern was characterized by prolonged pauses punctuated by gasping. Despite this marked alteration in respiratory pattern, minute ventilation and blood gases were not inordinately different from values obtained prior to denervation suggesting that hemodynamic and central control of respiration remained functional. This conclusion was reinforced by the finding that the response to hypoxemia was actually altered very little in magnitude and duration although the ventilatory response was determined by an increase in rate rather than in $V_{T}$ as is typical of vagally intact infants. This observation is supported further by a study in the neonatal piglet in which phrenic minute activity was similarly biphasic during acute hypoxemia before and after bilateral vagotomy (4).

In conclusion, this investigation has demonstrated that changes in lung mechanics characteristic of acute neonatal hypoxemia are not the result of small airway constriction modulated by efferent vagal activity. Also, despite the important role that afferent vagal input plays in establishing normal respiratory rhythm, this activity is not a requisite element of the biphasic hypoxic ventilatory response in the newborn. Finally, systemic cholinergic inhibition eliminated the initial transient ventilatory response to hypoxemia in the newborn suggesting that inhibition of carotid chemosensory activity occurred.

\section{REFERENCES}

1. Blanco CE, Hanson MA, Johnson P, Rigatto H 1984 Breathing pattern of kittens during hypoxia. J Appl Physiol 56:12-17

2. Cotton EK, Grunstein MM 1980 Effects of hypoxia on respiratory control in neonates at high altitude. J Appl Physiol 48:587-595

3. LaFramboise WA, Standaert TA, Woodrum DE, Guthrie RD 1981 Occlusion of pressures during the ventilatory response to hypoxemia in the newborn monkey. J Appl Physiol 51:1169-1174

4. Lawson EE, Long WA 1983 Central origin of biphasic breathing pattern during hypoxia in newborns. J Appl Physiol 55:483-488

5. LaFramboise WA, Guthrie RD, Standaert TA, Woodrum DE 1983 Pulmonary mechanics during the ventilatory response to hypoxemia in the newborn monkey. J Appl Physiol 55:1008-1014

6. Hogg JC. Williams J, Richardson JB, Macklem PT, Thurlbeck WM 1970 Age as a factor in the distribution of lower airway conductance and in the pathologic anatomy of obstructive lung disease. N Engl J Med 282:12831287

7. Otis AB, McKerrow CB, Bartlett RA, Mead J, Mcllroy NJ, Selverston J, Radford EP 1955 Mechanical Factors in distribution of pulmonary ventilation. J Appl Physiol 8:427-443

8. Woolcock AJ, Vincent NJ, Macklem PT 1969 Frequency Dependence of 
compliance as a test for obstruction in the small airways. $\mathbf{J}$ Clin Invest 48:1097-1106

9. Colebatch HJ, Halmagyi DF 1963 Effect of vagotomy and vagal stimulation on lung mechanics and circulation. J Appl Physiol 18:881-887

10. Colebatch HJ, Olsen CR, Nadel JA 1966 Effect of histamine, serotonin, and acetylocholine on the peripheral airways. J Appl Physiol 21:217-226

11. Vincent NJ, Knudson R, Leith DE, Macklem PT, Mead J 1970 Factors influencing pulmonary resistance. J Appl Physiol 29:236-243

12. Woolcock AJ, Macklem PT, Hogg JC, Wilson NJ, Nadel JA, Frank NR, Brain J 1969 Effect of vagal stimulation on central and peripheral airways in dogs. J Appl Physiol 26:806-813

13. Godal A, Belenky DA, Standaert TA, Woodrum DE, Grimsrud L, Hodson
WA, 1976 Application of the hot-wire anemometer to respiratory measurements in small animals. J Appl Physiol 40:275-277

14. Fowler WS 1950 Specific tests of pulmonary function. Meth in Med Res 2:181 .. 200

15. Whitelaw WA, Derenne J, Milic-Emili 1975 Occlusion Pressure as a measure of respiratory center output in conscious man. Respir Physiol 23:181-199

16. Innes RI, Nickerson M 1975 Atropine, scopolamine, and related antimus carinic drugs. In: Goodman LS, Gilman A (eds) The Pharmacological Basis of Therapeutics. Macmillian, New York, pp 514-532

17. Eyzaguirre C, Fidone SJ 1980 Transduction mechanisms in carotid body: glomus cells, putative neurotransmitters, and nerve endings. Am J Physio 239:C135-C152. 